\title{
Metformin improves ovarian insulin signaling alterations caused by fetal programming
}

\author{
María Florencia Heber'1, Silvana Rocío Ferreira1', Giselle Adriana Abruzzese1', Raíces Trinidad², Omar P Pignataro², \\ Margarita Vega ${ }^{3}$ and Alicia B Motta ${ }^{1}$ \\ ${ }^{1}$ Laboratorio de Fisio-patología Ovárica, Centro de Estudios Farmacológicos y Botánicos (CEFYBO), Consejo Nacional de Investigaciones Científicas y \\ Tecnológicas (CONICET), Facultad de Medicina, Universidad de Buenos Aires (UBA), Ciudad Autónoma de Buenos Aires, Buenos Aires, Argentina \\ ${ }^{2}$ Laboratorio de Endocrinología Molecular y Transducción de Señales, Instituto de Biología y Medicina Experimental - CONICET, Buenos Aires, Argentina \\ ${ }^{3}$ Laboratorio de Endocrinología y Biología Reproductiva, Hospital Clínico Universidad de Chile, Independencia, Santiago de Chile, Chile
}

Correspondence should be addressed to M F Heber or A B Motta: florencia.heber@gmail.com or aliciabmotta@yahoo.com.ar

\begin{abstract}
Insulin resistance is the decreased ability of insulin to mediate metabolic actions. In the ovary, insulin controls ovulation and oocyte quality. Alterations in ovarian insulin signaling pathway could compromise ovarian physiology. Here, we aimed to investigate the effects of fetal programming on ovarian insulin signaling and evaluate the effect of metformin treatment. Pregnant rats were hyperandrogenized with testosterone and female offspring born to those dams were employed; at adulthood, prenatally hyperandrogenized $(\mathrm{PH})$ offspring presented two phenotypes: irregular ovulatory (PHiov) and anovulatory (PHanov). Half of each group was orally treated with metformin. Metformin treatment improved the estrous cyclicity in both $\mathrm{PH}$ groups. Both PH groups showed low mRNA levels of Ir, Irs1 and Glut4. Irs2 was decreased only in PHanov. Metformin upregulated the mRNA levels of some of the mediators studied. Protein expression of IR, IRS1/2 and GLUT4 was decreased in both PH groups. In PHiov, metformin restored the expression of all the mediators, whereas in PHanov, metformin restored only that of IR and IRS1/2. IRS1 phosphorylation was measured in tyrosine residues, which activates the pathway, and in serine residues, which impairs insulin action. PHiov presented high IRS1 phosphorylation on tyrosine and serine residues, whereas PHanov showed high serine phosphorylation and low tyrosine phosphorylation. Metformin treatment lowered serine phosphorylation only in PHanov rats. Our results suggest that $\mathrm{PHanov}$ rats have a defective insulin action, partially restored with metformin. PHiov rats had less severe alterations, and metformin treatment was more effective in this phenotype.
\end{abstract}

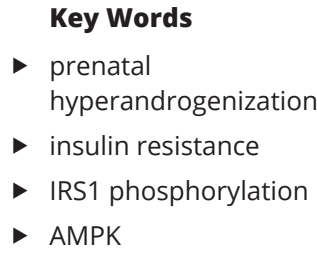

Journal of Endocrinology (2019) 240, 431-443

\section{Introduction}

Insulin resistance has been defined as a decreased ability of insulin to mediate metabolic actions on glucose uptake, glucose production and/or lipolysis, resulting in the need for increased amounts of insulin to achieve a given metabolic action (Rincon et al. 1996, DiamantiKandarakis \& Dunaif 2012). It has been proposed that insulin resistance is caused by a post-binding defect in the insulin signaling pathway and/or related to mutations in the insulin receptor (IR) gene (Imano et al. 1991, Nada et al. 2010). In skeletal muscle, cultured fibroblasts, adipocytes and endometrial cells, this postbinding defect has been characterized as a decrease in 
insulin-mediated PI3K activation associated with an increased phosphorylation of insulin receptor substrate 1 (IRS1) in serine residues and a decreased phosphorylation in tyrosine residues, which decrease insulin action (Paz et al. 1997, Fornes et al. 2010, Diamanti-Kandarakis \& Dunaif 2012). In the last decades, a large number of studies have identified the ovary as an important target tissue for insulin action (Diamanti-Kandarakis et al. 2008, Zhao et al. 2016). It is known that insulin is able to stimulate ovarian steroidogenesis (Poretsky et al. 1999, DiamantiKandarakis \& Dunaif 2012) and that an impaired glucose metabolism may reduce energy supply to granulosa cells and oocytes, compromising cell proliferation and oocyte development (Rice et al. 2005). In hyperandrogenic conditions such as polycystic ovary syndrome (PCOS), patients have an impaired glucose metabolism in granulosa cells (Zhao et al. 2016). Also, it has been hypothesized that hyperinsulinemia leads to hyperandrogenism and anovulation (Diamanti-Kandarakis et al. 2008).

The prenatal period is critical for fetal development because the fetus is vulnerable to alterations in its environment that can permanently alter the structure, homeostatic systems and functions of the body (Barker et al. 2006), leading to diseases in later life (FernandezTwinn et al. 2015). This phenomenon, called fetal programming, is known to be the cause of several diseases, including obesity, metabolic syndrome and diabetes (Godfrey \& Barker 2001). Several studies have reported that prenatal exposure to androgens is able to induce polycystic ovaries in rats (Demissie et al. 2008, Foecking et al. 2008), monkeys (Abbott et al. 2002) and sheep (Manikkam et al. 2006). It has also been reported that prenatal androgen excess can reprogram the expression of genes involved in gonad function in males (Recabarren et al. 2017). In addition, fetal programming mediated by prenatal hyperandrogenism is related to hyperinsulinemia, insulin resistance and other metabolic alterations such as cardiovascular disease, dyslipidemia and metabolic syndrome. All these alterations may affect several organs such as adipose tissue and liver or ovaries in different ways (Demissie et al. 2008, Nada et al. 2010, Amalfi et al. 2012, Abruzzese et al. 2016). However, the way in which fetal programming influences the insulin pathway in different tissues and its local consequences or effects are not yet known.

We have previously developed a murine model of fetal programming by prenatal hyperandrogenization which leads to PCOS features in female offspring (Heber et al. 2013, Abruzzese et al. 2016), and, among other characteristics, presents an insulin resistance state since puberty (Abruzzese et al. 2016).

Metformin, a very potent biguanide used as oral therapy for type 2 diabetes because of its antihyperglycemic actions, has been a popular choice of treatment not only for insulin resistance but also for the reproductive abnormalities found in PCOS patients (Hundal et al. 1992, Diamanti-Kandarakis et al. 2010). It is well known that metformin is able to reduce hepatic glucose synthesis (Hundal et al. 2000) and to increase glucose uptake in skeletal muscle and other tissues (Hundal et al. 1992, Galuska et al. 1994). Metformin is also able to regulate and/or stimulate the insulin signaling pathway directly in human granulosa cells and other cell types (DiamantiKandarakis et al. 2010, Rice et al. 2011, Xu et al. 2016). The mechanism of action of this drug in the different target tissues remains elusive. Several studies have demonstrated that metformin action on glucose uptake, downregulation of lipogenic genes and hepatic glucose production is due to AMP-activated protein kinase (AMPK) (Zhou et al. 2001, Kim et al. 2016), and it has been suggested that AMPK activation is responsible for the effects of metformin treatment in several tissues and cell types (Foretz et al. 2014). Particularly, Wu et al. demonstrated that metformin effects on follicular development and hyperandrogenism are regulated by the AMPK pathway (Wu et al. 2018).

In the present study, we aimed to uncover the effect of fetal programming on the insulin signaling pathway in the ovary and to evaluate the role of metformin in reversing the programming effects of hyperandrogenism.

\section{Materials and methods}

\section{Animals and experimental design}

Virgin female rats of the Sprague-Dawley strain mated with fertile males of the same strain were used. Three females and one male were housed in each cage under controlled conditions of light ( $12 \mathrm{~h}$ light, $12 \mathrm{~h}$ darkness) and temperature $\left(23-25^{\circ} \mathrm{C}\right)$. Animals received food and water ad libitum. Day 1 of pregnancy was defined as the morning on which spermatozoa were observed in the vaginal fluid. Between days 16 and 19 of pregnancy, rats were hyperandrogenized as described previously (Abruzzese et al. 2016). Briefly, pregnant rats $(N=15)$ received daily subcutaneous (SC) injections of $1 \mathrm{mg}$ of free testosterone (T-1500; Sigma) dissolved in $100 \mu \mathrm{L}$ of sesame oil (vehicle). The dose of testosterone administered resulted in circulating testosterone levels similar to those https://joe.bioscientifica.com

https://doi.org/10.1530/JOE-18-0520 (c) 2019 Society for Endocrinology Published by Bioscientifica Ltd. Printed in Great Britain 
in male rats (Wolf et al. 2002). A second group $(N=10)$ was SC injected with $100 \mu \mathrm{L}$ of vehicle only. Under the conditions of our animal facilities, spontaneous term labor occurs on day 22 of gestation. Pups were culled from litters to equalize group sizes (10 pups per mother). Females were separated from males at 21 days of age and randomly chosen. The female offspring $(N=60)$ from hyperandrogenized mothers formed the $\mathrm{PH}$ group, whereas the female offspring $(N=30)$ from mothers that had received vehicle-only formed the control group (Fig. 1). Animals were allowed free access to Purina rat chow (Cooperación, Argentina) and water. All the procedures involving animals were conducted in accordance with the Animal Care and Use Committee of Consejo Nacional de Investigaciones Científicas y Técnicas, Argentina, and the study was approved by the Ethics Committee of the School of Medicine of the University of Buenos Aires, Argentina. The estrous cycle was determined by vaginal smears taken daily from 45 to 70 days of age and from day 75 to 90 , to determine the reproductive phenotype. $\mathrm{PH}$ rats showed one of the two following phenotypes: (i) Anovulatory phenotype (PHanov): animals whose smears showed a constant metaestrus or diestrus stage or a combination of both and were thus considered to be non-cycling or (ii) Irregular ovulatory phenotype (PHiov): animals whose smears displayed the four stages of the estrous cycle: proestrus, estrus, metaestrus and diestrus, in disorder or with cycles of 7 days or longer (Karim et al. 2003, Abruzzese et al. 2016). From day 70 to the moment of killing, $50 \%$ of the animals of each group received a daily oral dose of $50 \mathrm{mg} / \mathrm{kg}$ of metformin

On the first diestrus after 90 days of age, the female offspring from each group were weighed, anesthetized with carbon dioxide and killed by decapitation. Trunk blood was collected and serum was separated and kept at $-80^{\circ} \mathrm{C}$ for further studies. The ovaries were extracted and conserved at $-80^{\circ} \mathrm{C}$. All animals were randomly assigned for each assay considering their littermates.

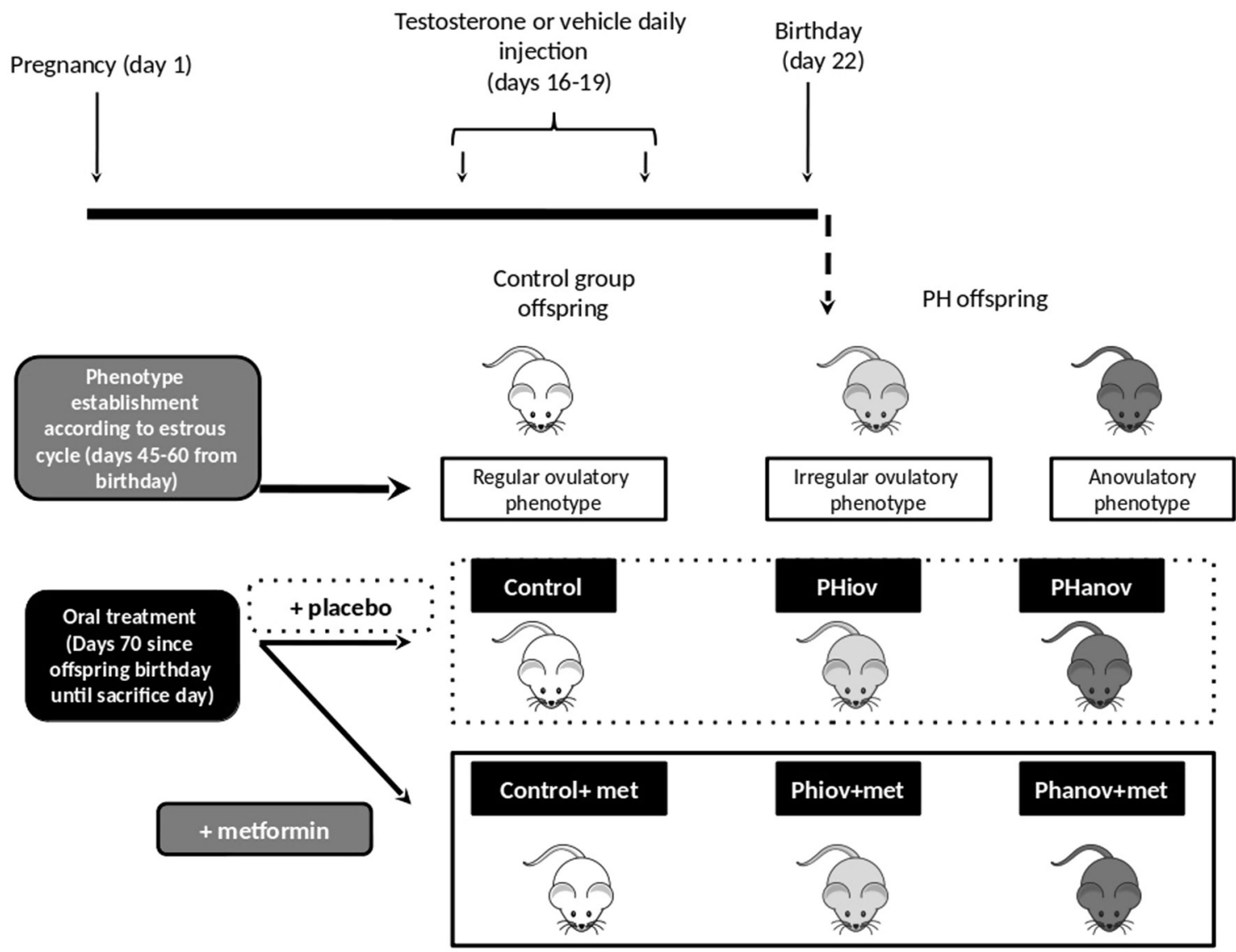

Figure 1

Schematic figure of the model used. Pregnant Sprague-Dawley rats were injected with $1 \mathrm{mg}$ of testosterone or vehicle from day 16 to 19 of gestation; birth occurs in day 22. Female offspring are separated from males, from day 45 to 60 of age the reproductive phenotype was established through analysis of the estrous cycle. Once the phenotype was established, half of each group received a $50 \mathrm{mg} / \mathrm{kg}$ dose of metformin administrated orally from day 70 until killing. During treatment, the estrous cycle was controlled to determine the reproductive phenotype at the time of killing. 
When assigning and equilibrating the number of animals from each litter, care was taken to prevent the maternal effect on the results.

At the moment of killing, the animals of the different groups showed no differences in body weight. Both $\mathrm{PH}$ groups presented hyperinsulinemia (insulin levels were measured by an ELISA kit; Abcam Insulin Human ELISA Kit); this state was restored by metformin in PHanov (control $=11.9 \pm 0.6 \mathrm{IU} / \mathrm{mL}$; PHiov $=12.9 \pm 0.75 \mathrm{IU} / \mathrm{mL} ;$ PHanov $=13.05 \pm 0.5 \mathrm{IU} / \mathrm{mL}$; control + metformin $=11.8 \pm 0.5 \mathrm{IU} / \mathrm{mL}$; $\mathrm{PHiov}+\mathrm{metformin}=12.42 \pm 0.3 \mathrm{IU} / \mathrm{mL}$; PHanov + metformin $=11.7 \pm 1.12 \mathrm{IU} / \mathrm{mL} ; \quad P<0.01)$. Also, both groups presented an insulin resistance state, determined by the homeostatic model assessment for insulin resistance (HOMA-IR), which was calculated according to the formula: fasting insulin $(\mathrm{IU} / \mathrm{mL}) \times$ fasting glucose $(\mathrm{mg} / \mathrm{dL}) / 405$ (Matthews et al . 1985). This state was reversed by metformin treatment in both PH groups (control $=3.23 \pm 0.38$; PHiov $=6.5 \pm 1.16$; PHanov $=6.3 \pm 0.69 ; \quad$ PHiov + metformin $=4.2 \pm 0.95$; PHanov + metformin $=4.65 \pm 1.27 ; \quad P<0.01)$. The ovaries from the rats of both phenotypes presented a high number of small prenatal follicles and ovarian cysts, as previously found at pubertal age (Abruzzese et al. 2016).

\section{Hormonal profile}

Testosterone and progesterone from seven animals per group were quantified using radioimmunoassay (RIA), as previously described (Amalfi et al. 2012). Briefly, steroids from serum samples were extracted with the same volume of diethyl ether three times. The extracts were collected and evaporated in a vacuum oven and stored at $-80^{\circ} \mathrm{C}$ until RIA was performed. The utility range of testosterone assay was $25-1600 \mathrm{pg}$. The intra- and inter-assay variations were 7.5 and $15.1 \%$, respectively. Results are expressed as pg testosterone/mL serum. Progesterone antiserum was highly specific for progesterone and showed low cross-reactivity. The intra- and inter-assay coefficients of variation were 10.9 and $12.8 \%$, respectively. Values are expressed as $\mathrm{ng} / \mathrm{mL}$ of serum progesterone. Serum estradiol levels were quantified with Cobase immunoassay analyzers using an Electro Chemiluminescence Immuno Assay (ECLIA) following the manufacturer's instructions. The intra- and inter-assay coefficients of variation (CVs) were 13.2 and $7.08 \%$. The estradiol-to-testosterone ratio $(\mathrm{E} 2 / \mathrm{T})$ was determined as a marker of ovarian function (Amato et al. 2011).

\section{Insulin pathway}

\section{Gene expression}

The mRNA levels of Ir, Irs1, Irs2 and glucose transporter 4 (Glut4) were measured by real-time PCR analysis. Total mRNA from ovarian tissue ( $n=10$ samples per group) was extracted at 90 days of age using RNAzol RT (MRC gene; Molecular Research Center, Cincinnati, OH, USA), following the manufacturer's instructions. cDNA was synthesized from 500ng mRNA using random primers. Real-time PCR analysis was performed from this cDNA by means of the real mix B124-100 (Biodynamics SRL, Caba, Argentina) and the primers according to the analysis. The amplified products were quantified by fluorescence, using the Rotor Gene 6000 Corbette. Results are expressed as a fold change of the control. The 60s ribosomal protein L32 (Rpl32) and proteasome subunit beta type-2 (Psmb2) were used as reference genes. Gene expression was quantified using the comparative CT method (also known as the 2- $\Delta \triangle \mathrm{CT}$ method) (Swillens et al. 2008). Primers are shown in Table 1.

\section{Protein expression and phosphorylation}

Western blotting was performed as previously described (Amalfi et al. 2012). Ovarian tissue ( $n=6$ per group) was lysed for $20 \mathrm{~min}$ at $4^{\circ} \mathrm{C}$ in lysis buffer $(20 \mathrm{mM}$ Tris- $\mathrm{HCl}$, $\mathrm{pH}=8.0,137 \mathrm{mM} \mathrm{NaCl}, 1 \%$ Nonidet P-40 and $10 \%$ glycerol) supplemented with protease inhibitors (Protease Inhibitor Cocktail P8340, Sigma Aldrich). The lysate was centrifuged at $4^{\circ} \mathrm{C}$ for $10 \mathrm{~min}$ at $10,000 \mathrm{~g}$ and the pellet was discarded. Protein concentrations in the supernatant were measured by the Bradford assay (Bio-Rad) (Bradford 1976). Total proteins $(50 \mu \mathrm{g})$ were denatured and separated on a SDS-PAGE (10\%) and transferred onto nitrocellulose membranes (GE Healthcare, Life Sciences). Membranes were blocked for $1.5 \mathrm{~h}$ in TBS $(4 \mathrm{mM}$ Tris--HCl, $\mathrm{pH}=7.5$, $100 \mathrm{mM} \mathrm{NaCl}$ ) containing bovine serum albumin (5\%) at room temperature, and, subsequently, the membranes were washed three times for $7 \mathrm{~min}$ each in TBST $(4 \mathrm{mM}$ Tris-HCl, $\mathrm{pH}=7.5,100 \mathrm{mM} \mathrm{NaCl}, 0.1 \%$ Tween 20 ) and then incubated at $4^{\circ} \mathrm{C}$ with rocking overnight with primary antibodies (listed in Table 2). Then, the membranes were

Table 1 List of primers used in the real-time PCR.
Gene

Forward primer $\left(5^{\prime}-3^{\prime}\right)$ Irs1 Irs2

Glut4

Psmb2 Rpl32 ATG GGA CCA CTG TAC GCT TC TCG ATC CGT TCT CGA AGA CT TGT GCC AAG CAA CAA GAA AG ACG GTT TCA GAG CAG AGG AA GGA AGT CTG TTC GGG TGT GT ACA TCT GCT TCA GTG TGC TG GGC CGG GAC ACT ATA CCC TA GGA GGA AAT CAT GCC ACC CA TCG GAG TCG GAC CCC TTA TC TGT AGT AAA GTG CTG GCC CC TGG TCC ACA ATG TCA AGG (c) 2019 Society for Endocrinology Published by Bioscientifica Ltd. Printed in Great Britain 
Table 2 List of antibodies used.

\begin{tabular}{llll}
\hline Antibody & & Dilution \\
\cline { 1 - 1 } Anti-B IR (Santa Cruz (c-19)) & & $1: 1000$ \\
Anti-IRS1/2 (Santa Cruz (sc-559)) & & $1: 500$ \\
Anti-IRS1 pY612 (Abcam (ab66153)) & & $1: 800$ \\
Anti-IRS1 pS307 (Santa Cruz (sc-33959)) & & $1: 300$ \\
Anti-GLUT 4 (Novus Biological (51262)) & & $1: 500$ \\
Anti-AMPK (Cell Signaling \#2532) & & $1: 1000$ \\
Anti-AMPKpT172 (Cell Signaling \#2535) & & $1: 500$ \\
Anti-AKT (Cell Signaling \#9272) & & $1: 1000$ \\
Anti-AKTpS473 (Cell Signaling \#9271) & & $1: 1000$ \\
Anti-B-actin (Cell Signaling \#4967) & & $1: 5000$ \\
Anti-B-Tubulin (Abcam (ab131205)) & & $1: 1500$ \\
Anti-Mosue IgG H\&L (HRP) (Abcam (ab6728)) & & $1: 5000$ \\
Goat Anti-Rabbit IgG-HRP (Santa Cruz (sc-2030)) & $1: 2000$ \\
\hline
\end{tabular}

washed three times for $7 \mathrm{~min}$ each in TBST and incubated at room temperature for $1 \mathrm{~h}$ with peroxidase-conjugated species-specific anti-rabbit and anti-mouse IgG while being rocked. Then, after three washings of $7 \mathrm{~min}$ each with TBST, the bound antibodies were detected with an enhanced chemiluminescence system, ImageQuant LAS 500 (GE Healthcare, Life Sciences). Band intensities were quantified by scanning densitometry by using Image J $1.44 \mathrm{p}$ software (Wayne Rasband, NIH) and normalized relative to B-actin and/or B-tubulin and expressed as arbitrary units (AU).

\section{Statistical analysis}

Statistical analyses were carried out using the program GraphPad Instat (GraphPad software). A two-way ANOVA with a Tukey post hoc analysis was performed to compare the main effects of prenatal hyperandrogenization and metformin treatment. (Control, PHiov and PHanov without metformin treatment and control, PHiov and PHanov with metformin treatment). All data are presented as mean + S.E.M. Statistical significance was considered as $P<0.05$.

\section{Results}

\section{Prenatal hyperandrogenization alters estrous cycle}

Vaginal smears from 75 to 90 days of age showed that $49-50 \%$ of the PH group displayed an irregular ovulatory cycle (PHiov) and that 38-43\% displayed anovulation (PHanov). All control animals displayed a normal estrous cycle. After metformin treatment, $40-60 \%$ of the PHiov rats (determined irregular ovulatory from days 45 to 70 ) recovered their cyclicity. In contrast, only $11-27 \%$ of the
PHanov rats (determined anovulatory from days 45 to 70) recovered their cyclicity, whereas $47-78 \%$ of them recovered their cyclicity only partially, thus becoming irregular ovulatory (Fig. 2A).

\section{Prenatal hyperandrogenization impairs hormonal profile}

Serum testosterone levels were higher in the PHanov group than in the control group (Fig. $2 \mathrm{~B}, P<0.01$ ). Metformin treatment did not modify the testosterone levels of the PHiov or PHanov groups, but tended to diminish those of the PHanov group. Serum estradiol levels were lower for both $\mathrm{PH}$ groups compared to the control group. Metformin treatment had no effect on serum estradiol (Fig. $2 \mathrm{C}, P<0.01)$. The estradiol-to-testosterone ratio was decreased in both $\mathrm{PH}$ groups; metformin treatment had no effect (Fig. 2D, $P<0.01$ ). We found no differences between any of the groups when analyzing the progesterone serum levels (Fig. 2E, $P>0.05$ ).

\section{Metformin treatment promotes the phosphorylation of AMPK}

To confirm that metformin treatment was effective in the ovary, we measured the phosphorylation of AMPK. Band intensities were quantified using scanning densitometry and normalizing AMPKpT172 relative to AMPK. In both $\mathrm{PH}$ groups, metformin treatment increased the phosphorylation of AMPK. This phosphorylation was higher in the PHiov group than in the PHanov group (Fig. 3, $P<0.01$ ).

\section{Prenatal hyperandrogenization modifies the expression of insulin pathway mediators}

IR

Ir mRNA levels were lower in both $\mathrm{PH}$ groups than in the control group (Fig. 4A, $P<0.01$ ), but metformin treatment restored the levels to those of the control group only in the PHiov group (Fig. 4A, $P<0.05$ ).

IR protein expression was lower in the PHanov than in the control group (Fig. 4B, $P<0.05$ ), and although in the PHiov group the protein band observed was less intense, this was not statistically different. Metformin treatment restored IR protein expression to control values only in the PHiov group. In the PHanov group, metformin treatment led to an increase in IR protein expression but was not able to normalize it to control values. 
A

\begin{tabular}{|l|l|}
\hline Phenotype & $\%$ of rats \\
\hline Control ( regular cycle) & $100 \%$ \\
\hline PHiov (irregular cycle) & $49-50 \%$ \\
\hline PHanov (anovulation) & $38-43 \%$ \\
\hline
\end{tabular}

B

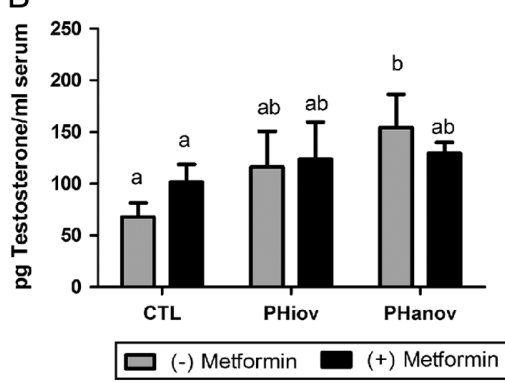

D

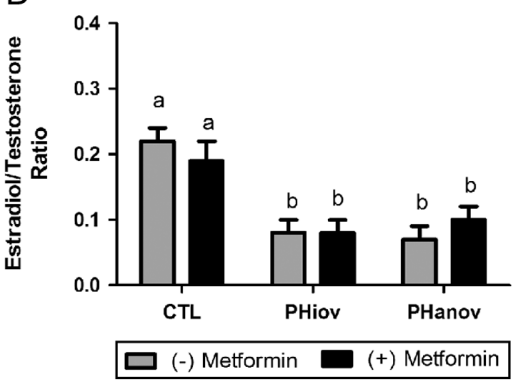

\begin{tabular}{|l|l|l|}
\hline Control ( regular cycle) & After metformin treatment & $100 \%$ regular cycle \\
\hline PHiov (irregular cycle) & After metformin treatment & $40-60 \%$ to regular cycle \\
\hline \multirow{2}{*}{ PHanov (anovulation) } & After metformin treatment & $11-27 \%$ to regular cycle \\
\cline { 3 - 3 } & & $47-78 \%$ to irregular cycle \\
\hline
\end{tabular}

C

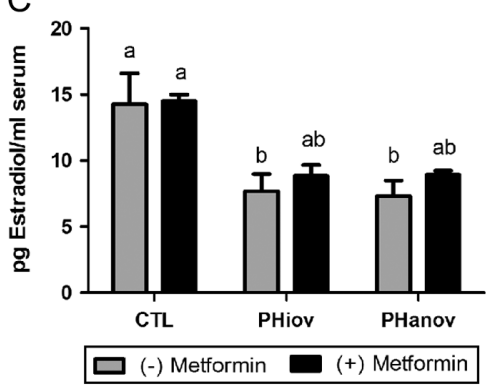

E

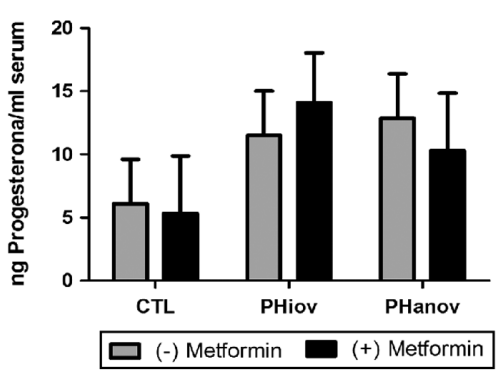

Figure 2

Hormonal profile (A) Proportion of rats corresponding to each reproductive phenotype before and after metformin treatment. (B) Serum testosterone levels of control (CTL) and $\mathrm{PH}$ groups (irregular ovulatory (PHiov) and anovulatory (Phanov)); (C) Serum estradiol levels of control (CTL) and $\mathrm{PH}$ groups (irregular ovulatory (PHiov) and anovulatory (Phanov)); (D) Estradiol to testosterone ratio of control (CTL) and $\mathrm{PH}$ groups (irregular ovulatory (PHiov) and anovulatory (Phanov)); (E) Serum progesterone levels of control (CTL) and PH groups (irregular ovulatory (PHiov) and anovulatory (Phanov)); gray bars: groups without metformin treatment, black bars: groups with metformin treatment. Each column represents the mean + S.E.M. from seven animals per group. Data were analyzed by two-way ANOVA, with post hoc Tukey's test. a vs b; $P<0.05$.

\section{IRS1/2}

Irs1 mRNA levels were lower in both PH groups than in the control group (Fig. 5A, $P<0.01$ ), whereas Irs 2 mRNA levels were lower only in the PHanov group than in the control group (Fig. 5B, $P<0.01$ ). Metformin treatment restored IRS1 mRNA levels to control values in both the PHiov and PHanov groups (Fig. 5A, $P<0.01$ ), but not those of IRS2.

IRS1 protein expression was lower in both $\mathrm{PH}$ groups than in the control group (Fig. 5C, $P<0.01$ ), and, after metformin treatment, the expression of IRS1 tended to increase but was not statistically different (Fig. 5C, $P>0.05$ ).

To analyze the activation of the insulin signaling pathway, we next studied the phosphorylation of IRS1 in two different residues: serine 307 and tyrosine 612 . Tyrosine phosphorylation was lower in the PHanov group than in the control and PHiov groups (Fig. 5D, $P<0.01$ ). In the PHiov group, phosphorylation was similar to that in the control group. Metformin treatment did not modify the IRS1 tyrosine phosphorylation in any of the groups. IRS1 serine phosphorylation was higher in the PHiov group than in the control group (Fig. 5E, $P<0.01$ ) and higher in the PHanov group than in the control and PHiov groups (Fig. 5E, $P<0.01$ ). Metformin treatment decreased serine phosphorylation of IRS1 in the PHanov group, restoring it to control values (Fig. 5E, $P<0.01$ ).

\section{GLUT4}

Glut4 transcript levels were lower in the PHiov and PHanov groups than in the control group (Fig. 6A, $P<0.01)$. Metformin treatment restored the mRNA levels of the PHiov group to control values, but although it also had an effect on the levels of the PHanov group, these levels did not reach the control values (Fig. 6A, $P<0.01$ ).

Protein levels of GLUT4 were lower in both the PHiov and PHanov groups than in the control group (Fig. 6B, $P<0.01)$. These decreased levels of GLUT4 were reversed after metformin treatment only in the PHiov group (Fig. 6B, $P<0.01$ ).

\section{AKT phosphorylation}

There was no difference in AKT phosphorylation between any of the groups studied (Fig. 7, P>0.05)

\section{Discussion}

It is well known that alterations in fetal nutrition and endocrine status result in developmental adaptations that permanently change the structure, physiology and metabolism of the fetus, predisposing to disease during the adult life (Godfrey \& Barker 2001). Finding an 


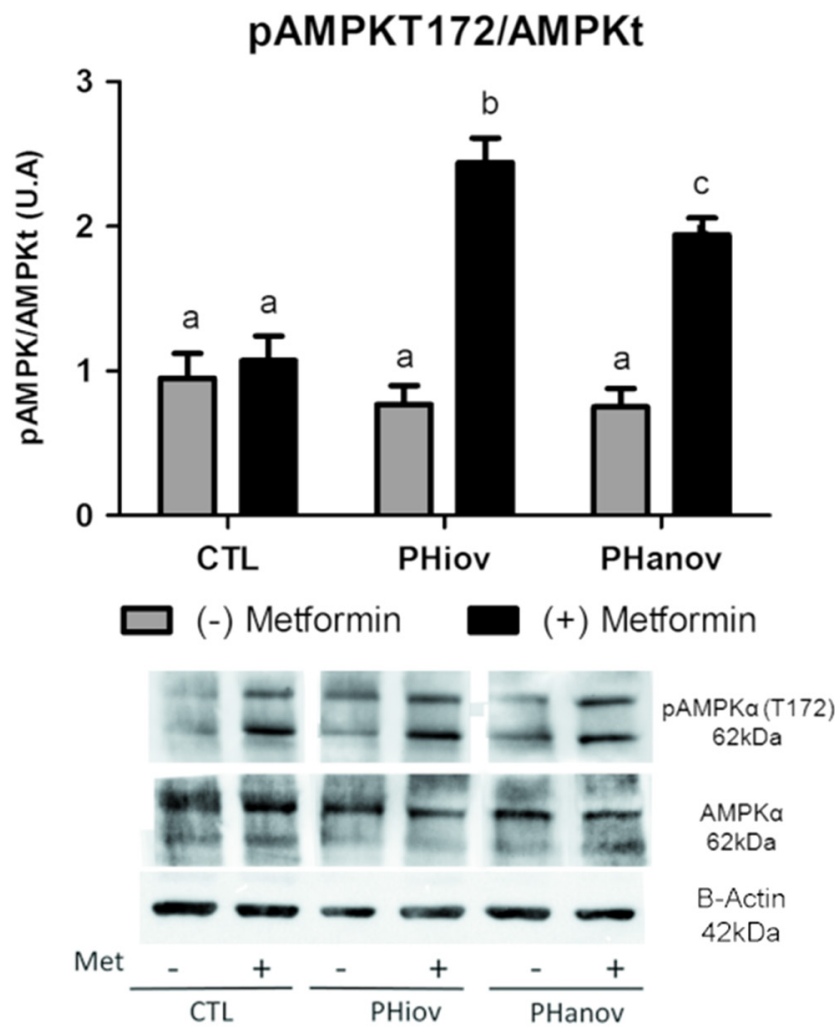

Figure 3

Metformin treatment: ratio between AMPKpT172 and AMPK of control (CTL) and PH groups (irregular ovulatory (PHiov) and anovulatory (PHanov)); gray bars: groups without metformin treatment, black bars: groups with metformin treatment. Each column represents the mean + S.E.M., from six animals per group. Data were analyzed by two-way ANOVA, with post hoc Tukey's test. a vs b; $P<0.05$. For the Western blot analysis, representative images for all groups are shown; all the bands for each picture come always from the same gel, but they may be spliced for clarity.

experimental model to study these alterations has proved to be difficult (Manikkam et al. 2006, Demissie et al. 2008, Foecking et al. 2008, Abbott et al. 2010). There is evidence that fetal programming caused by androgen excess can induce long-term metabolic alterations such as insulin resistance, impaired insulin secretion and hyperinsulinemia (reviewed in Padmanabhan et al. 2006).

Due to the multigenic character of insulin resistance, its pathogenesis is complex, controversial and tissue specific. Thus, the mechanisms involved in insulin resistance are not yet clear. Insulin resistance has traditionally been studied in classical insulin target organs such as skeletal muscle and adipose tissue (Book \& Dunaif 1999, Corbould 2007). However, in view of the important role of insulin in ovarian function and the controversy about insulin signaling in the ovary (Wu et al. 2003,
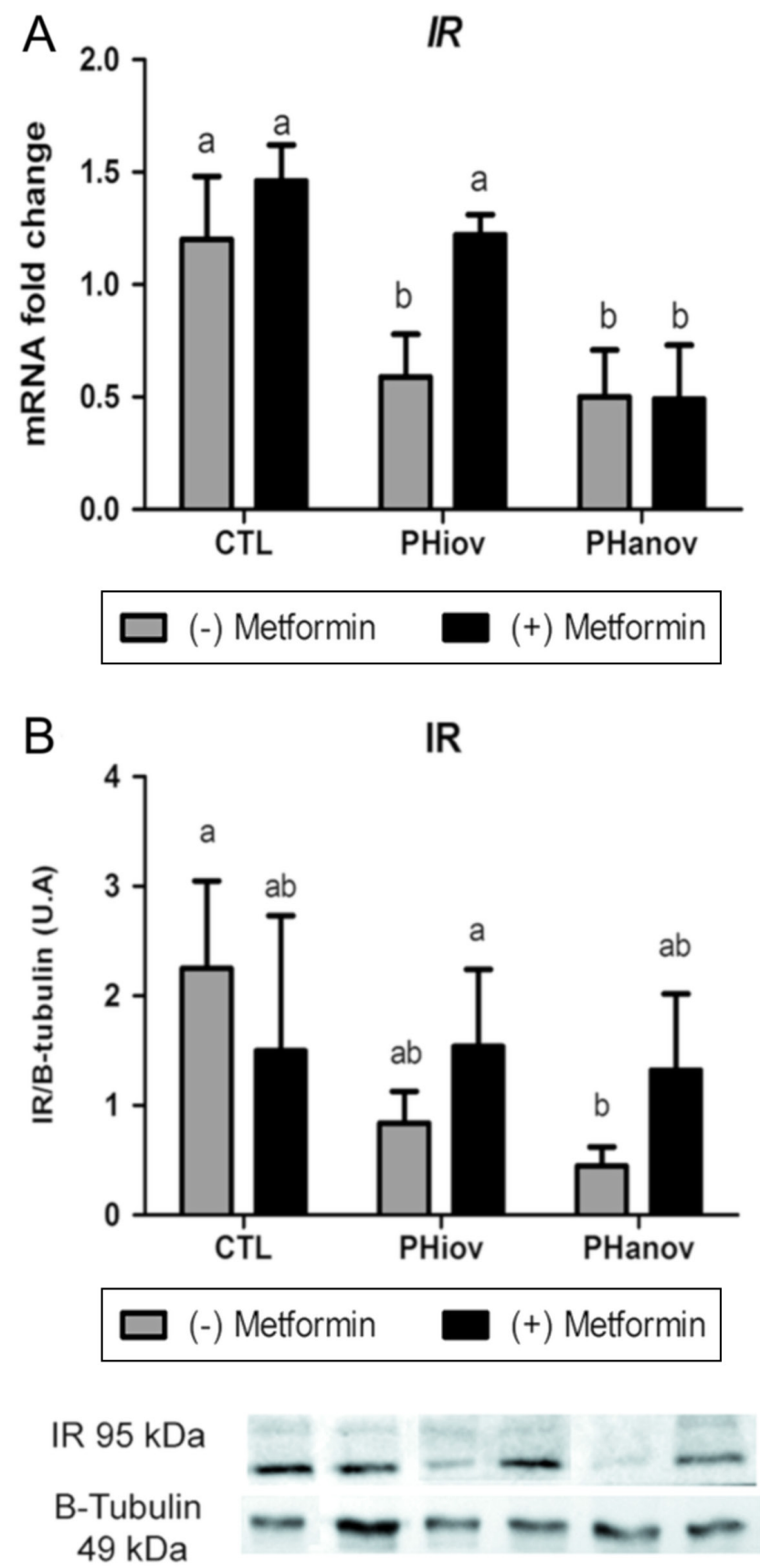

Figure 4

Gene and protein expression of insulin receptor (IR). The graphs correspond to (A) mRNA abundance of the $I R$ gene relative to $L 32 \mathrm{mRNA}$ levels; (B) protein levels of IR relative to B-tubulin of control (CTL) and PH groups (irregular ovulatory (PHiov) and anovulatory (PHanov)); gray bars: groups without metformin treatment, black bars groups with metformin treatment. Each column represents the mean + S.E.M.; from ten animals per group for qPCR analysis and six animals per group for western blot. Data were analyzed by two-way ANOVA, with post hoc Tukey's test. a vs b; $P<0.05$. For the Western blot analysis, representative images for all groups are shown; all the bands for each picture come always from the same gel, but they may be spliced for clarity. 

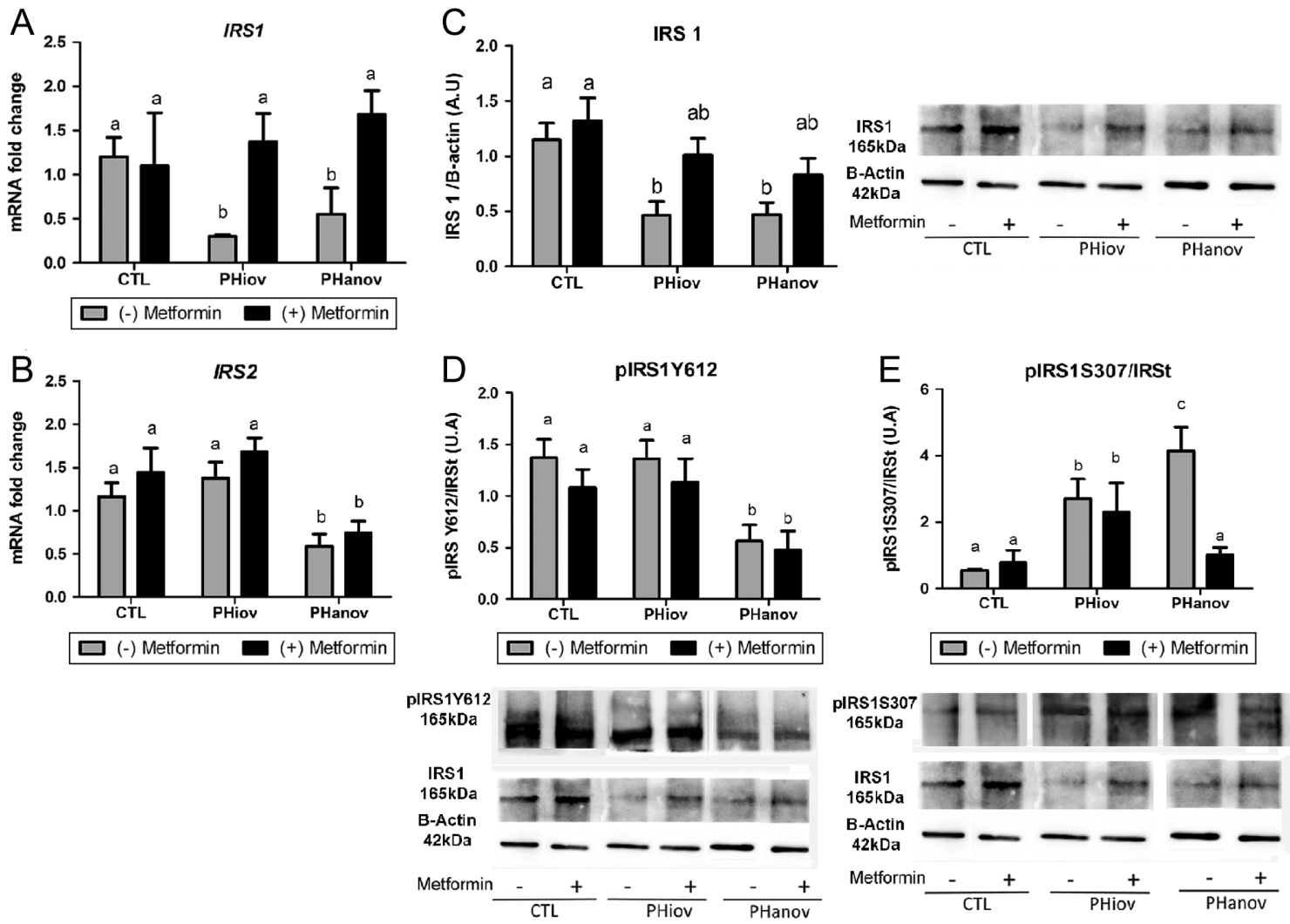

\section{Figure 5}

Graphs correspond to (A) mRNA abundance of the IRS1 gene relative to L32 mRNA levels; (B) mRNA abundance of the IRS2 gene relative to L32 mRNA levels; (C) protein levels of IRS1/2 relative to B-actin; (D) ratio between pIRS1Y612 and IRS1; (E) ratio between pIRS1S307 and IRS1 gray bars: groups without metformin treatment, black bars: groups with metformin treatment. A representative image of the media of bands obtained from each group is shown. Each column represents the mean + S.E.M.; from ten animals per group for qPCR analysis and six animals per group for western blot. Data were analyzed by two-way ANOVA, with post hoc Tukey's test. a vs b; $P<0.05$. For the Western blot analysis, representative images for all groups are shown; all the bands for each picture come always from the same gel, but they may be spliced for clarity.

Diamanti-Kandarakis et al. 2008), it is also important to add some evidence about the insulin pathway in the ovary. In that sense, the aim of the present study was to provide evidence of whether fetal programming, as a consequence of prenatal androgen excess, alters the metabolic insulin pathway and also whether metformin treatment could be enough to restore the alterations. In accordance to our previous reports on pubertal rats (Abruzzese et al. 2016), in the present work, we were able to reproduce a PH model, which showed two phenotypes: a PHiov phenotype, with incipient hyperandrogenism, low levels of estradiol and altered estrous cycle, and a PHanov phenotype, characterized by more severe hyperandrogenism, low estradiol levels, altered ovarian function and anovulation. In the present study, we could establish that our model displays ovulatory dysfunctions, ovarian cysts and an altered hormonal profile, with hyperandrogenism and low levels of estradiol. Although no alterations were found regarding progesterone,
LH and FSH levels (data not shown). These results are in accordance with the findings in PCOS patients and to other reports of prenatal hyperandrogenization models (Wu et al. 2010, Amalfi et al. 2012). We also found in both $\mathrm{PH}$ phenotypes that the estradiol-to-testosterone ratio was decreased. This ratio is considered to be an indicator of ovulatory dysfunction, and in PCOS, it is associated with oligo and anovulation (Amato et al. 2011).

We found two distinctive reproductive phenotypes that did not depend on the hyperandrogenized mother, as we found animals displaying the anovulatory phenotype had siblings that presented an ovulatory phenotype. It has been shown that developmental plasticity, in response to prenatal androgens, allows different responses to the same stimulus (Bateson et al. 2014). In addition, it is known that intrauterine position can influence fetuses' exposure to hormones, nutrients and other factors altering sexual development and function, thus conditioning adulthood (Zielinski et al. 1991, Ryan \& 
A

\section{GLUT4}

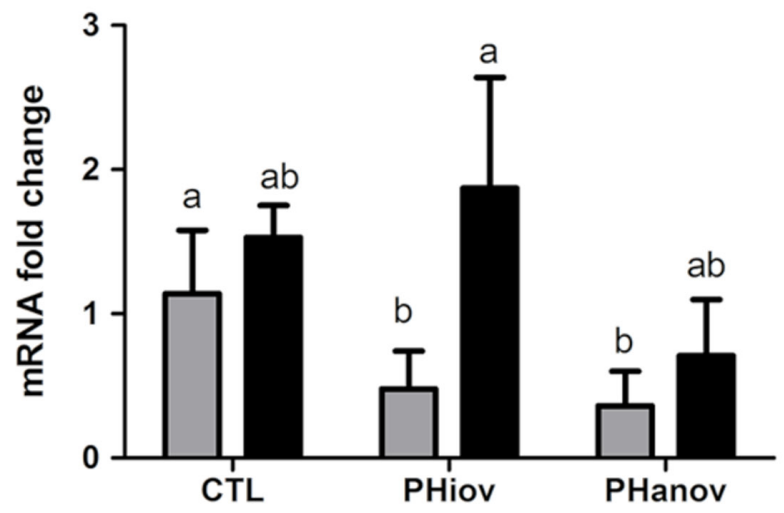

$\square(-)$ Metformin $\square(+)$ Metformin

B
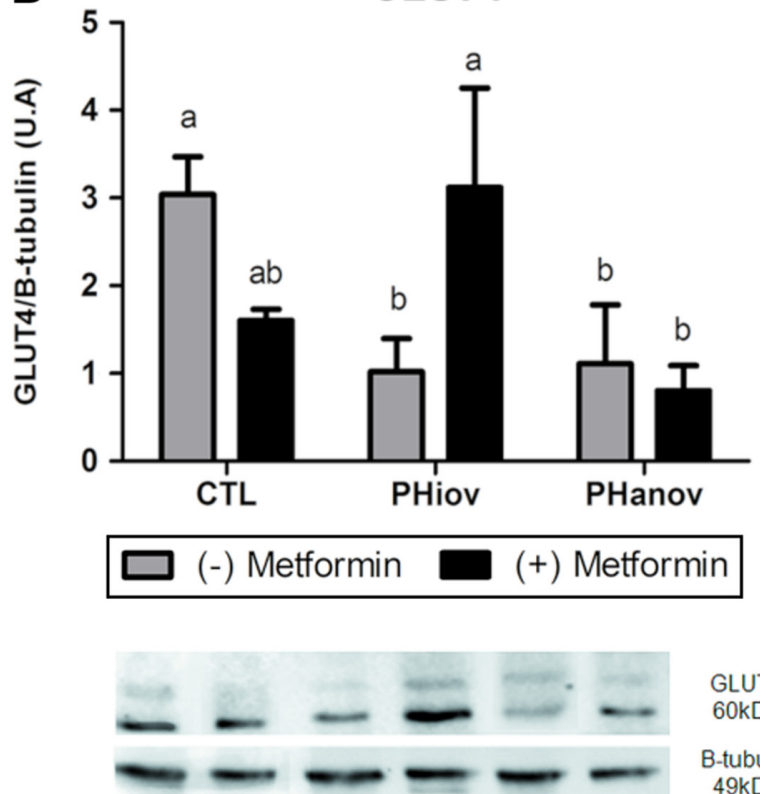

GLUT4 $60 \mathrm{kDa}$

B-tubulin $49 \mathrm{kDa}$

\section{Figure 6}

Glucose transporter. The graphs correspond to (A) mRNA abundance of Glut4 relative to $L 32$ mRNA levels; (B) protein levels of GLUT4 relative to $\mathrm{B}$-tubulin of control and $\mathrm{PH}$ groups (irregular ovulatory (PHiov) and anovulatory (PHanov)); a representative image of the media of bands obtained from each group is shown; gray bars: groups without metformin treatment, black bars: groups with metformin treatment. Each column represents the mean + S.E.M.; from six animals per group for western blot. Data were analyzed by two-way ANOVA, with post hoc Tukey's test. a vs b; $P<0.05$. For the Western blot analysis, representative images for all groups are shown; all the bands for each picture come always from the same gel, but they may be spliced for clarity.

Vandenbergh 2002). Therefore, the mechanism which leads to these two phenotypes may involve not only developmental plasticity (Bateson et al. 2014), but also intrauterine position. In fact, a study by Jahanfar et al. (1995) showed plastic phenotypes in monozygotic and
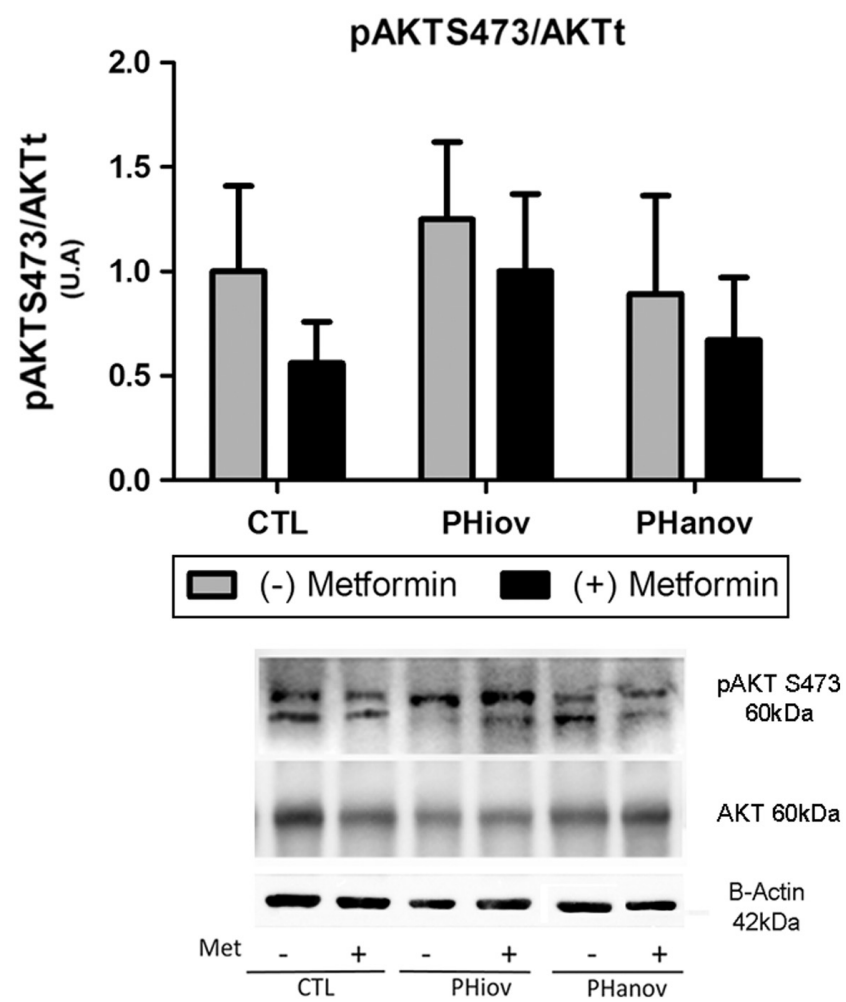

Figure 7

AKT phosphorylation. The graph correspond to ratio of AKTpS473 and total AKT of control (CTL) and prenatally hyperandrogenized $(\mathrm{PH})$ groups (irregular ovulatory (PHiov) and anovulatory (PHanov)); a representative image of the media of bands obtained from each group is shown; gray bars: groups without metformin treatment, black bars: groups with metformin treatment. Each column represents the mean + S.E.M.; from animals six animals per group. Data were analyzed by two-way ANOVA, with post hoc Tukey's test. a vs b; $P<0.05$. For the Western blot analysis, representative images for all groups are shown; all the bands for each picture come always from the same gel, but they may be spliced for clarity.

dizygotic twins with PCOS, where one of the twins may show polycystic ovaries with hyperandrogenism and/or menstrual dysfunction, while the other twin may show some of the features but not all of them, or none (Jahanfar et al. 1995).

Coupled with these endocrine and reproductive alterations, adult rats from both phenotypes presented an insulin resistance state, characterized by systemic hyperglycemia and hyperinsulinemia. These deregulations caused by prenatal exposure to androgens improved after treatment with a clinically relevant metformin concentration equivalent to that used to treat PCOS patients (Mathur et al. 2008). As expected, the insulin resistance state was reversed by metformin treatment, and this correlated with the fact that metformin is able to improve glucose metabolism (Giannarelli et al. 2003, Diamanti-Kandarakis et al. 2010). Concomitantly 
with these observations, we also observed a recovery in reproductive abnormalities, characterized by an improvement of the estrous cycle abnormalities found in both phenotypes of $\mathrm{PH}$ rats. These data are in agreement with that observed in PCOS patients that undergo metformin treatment (Lord et al. 2003).

The ovary is an important organ for insulin action. There is extensive evidence demonstrating a direct action of insulin on ovarian steroidogenesis and the importance of the insulin signaling pathway in the control of ovulation and oocyte quality (summarized in Fig. 8) (DiamantiKandarakis et al. 2008, Dupont \& Scaramuzzi 2016, Zhao et al. 2016). A defective insulin action can impair the metabolic pathway of granulosa cells in PCOS (DiamantiKandarakis et al. 2008), whereas hyperinsulinemia has both a direct and an indirect role in anovulation by altering folliculogenesis and steroidogenesis (Franks et al. 2000). In this work, we found that several mediators of the metabolic insulin signaling cascade, such as IR, IRS1, IRS2 and GLUT4, were altered in the ovarian tissue of both the $\mathrm{PH}$ phenotypes at both gene and protein expression levels, as well as the phosphorylation of IRS1. The depths of these alterations were different between phenotypes, PHanov being the one that presented deeper alterations. The most notable difference in the expression pattern between phenotypes was that observed in the mRNA levels of IRS2, which were downregulated only in the PHanov phenotype. This finding is in agreement with those of Burks et al. who found that mice lacking IRS2 presented anovulatory ovaries (Burks et al. 2000). These results may highlight the role of IRS2 as a fundamental mediator of ovulatory dysfunctions in hyperandrogenized conditions as PCOS, which may be, at least in part, responsible for the phenotype diversity regarding the estrous cycle. It is known that insulin exerts its action through phosphorylation of tyrosine residues of various substrates, including IRS1 (White 2002). IRS1 phosphorylation leads to the activation of the PI3K and Akt signaling pathways, which, among other actions, stimulate the translocation of glucose transporters to the cell membrane to allow glucose uptake (Watson \& Pessin 2001). In hyperandrogenic conditions, as PCOS, increased serine phosphorylation of IR and IRS1 in several tissues results in the inhibition of insulin action (Saltiel \& Kahn 2001, Draznin 2006). Our results suggest that PHanov rats, which showed increased serine phosphorylation of IRS1 and deficient tyrosine phosphorylation, have a defective insulin action in the ovary that would inhibit glucose uptake. In contrast, although PHiov rats

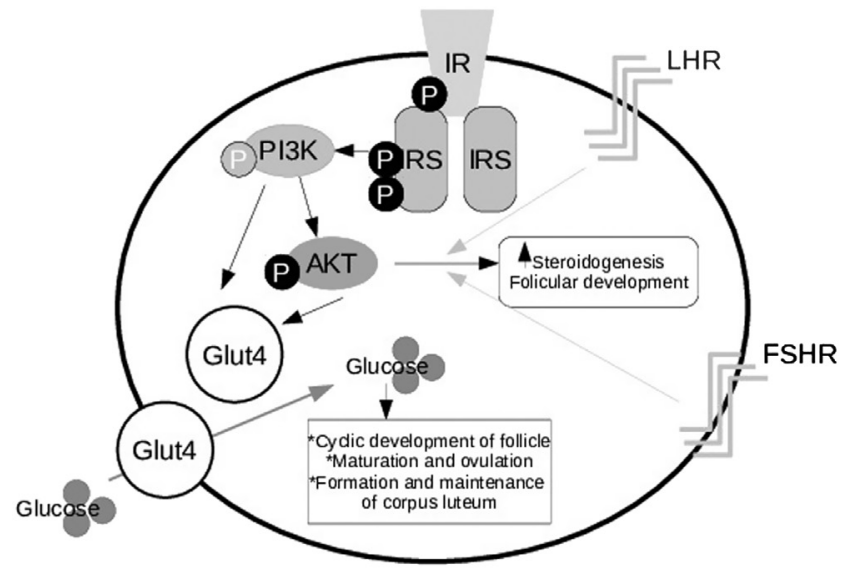

\section{Figure 8}

Insulin pathway and ovarian function. Insulin binding to its receptor promotes the autophosphorylation of the insulin receptor (IR) which phosphorylates intracellular substrates (IRS), initiating signal transduction pathways mediating the pleiotropic actions of insulin. The major pathway for the metabolic actions of insulin is mediated through activation of $\mathrm{PI} 3-\mathrm{K}$ and Akt, resulting in the translocation for the insulin-responsive glucose transporter, GLUT4, from intracellular vesicles to the plasma membrane. Glucose is essential for oocyte development and ovulation. The Akt pathway also promotes the expression of steroidogenic enzymes, thus stimulating steroidogenesis and follicular development. The action of insulin on steroidogenesis is enhanced by the binding of LH and FSH to its receptors.

presented increased serine phosphorylation, IRS1 tyrosine phosphorylation was higher, allowing a compensatory activation of insulin signaling, this could in turn allow some level of glucose uptake by ovarian cells. Taking all into consideration, the PHanov phenotype not only presented more reproductive alterations but also displayed an impaired ovarian insulin signaling. This was also reported by other authors who showed an association between hyperandrogenic states and hyperinsulinemia, highlighting a cross-talk between insulin signaling and hormonal alterations (Diamanti-Kandarakis et al. 2008, Diamanti-Kandarakis \& Dunaif 2012).

Since glucose is an important energetic substrate essential for the metabolic and physiological functions of the ovary (Dupont \& Scaramuzzi 2016), any alteration in the insulin pathway that inhibits glucose uptake could compromise ovarian physiology. Thus, the alterations found in the insulin pathway could contribute to the reproductive alterations found in the ovary of hyperandrogenized rats. Moreover, the difference in the depth of the alterations found between the two groups of PH rats could be contributing to explain the two welldefined phenotypes found. The PHanov group presented decreased gene and protein expression and increased serine phosphorylation of IRS1, thus having an impaired 
insulin action which would compromise glucose uptake (Draznin 2006). Since glucose is known to be necessary for follicle development, maturation and ovulation (Dupont \& Scaramuzzi 2016), we consider that the condition of anovulation in the PHanov phenotype could be partly explained by the impaired glucose uptake caused by the alterations in the insulin signaling pathway. On the other hand, despite the downregulation found in some of the mediators of the insulin signaling cascade, as IR and IRS1, the PHiov phenotype presented certain level of activation of the pathway given by the phosphorylation of IRS1 in the tyrosine residue, which allows insulin action and glucose uptake (Watson \& Pessin 2001). Surprisingly, we did not find any alterations in Akt phosphorylation in the PH groups although we did found alterations in GLUT4 expression and in IRS1 signaling; this shows in accordance to other studies that an impairment in insulin signaling can occur despite normal Akt activation (reviewed in Diamanti-Kandarakis \& Dunaif 2012).

We also found evidence that metformin acts as a gene and protein expression modulator in the ovary. This is in agreement with that found by other authors who showed that this biguanide is able to regulate both gene and protein expression in several tissues (Tosca et al. 2010, Viollet et al. 2012). The effects on the alterations after metformin treatment were found to be also phenotypically different. While both PH phenotypes presented upregulations of IR and IRS1, only the PHiov phenotype presented recovery of these molecules. It is important to point out that metformin was also able to reduce serine phosphorylation of IRS1 in the PHanov phenotype. This result is in accordance with that by Ma et al. (2018) who observed that metformin is able to reduce serine phosphorylation of IRS- 1 in human granulosa cells from PCOS patients (Ma et al. 2018) thus partially restoring the functionality of the insulin signaling due to the basal tyrosine phosphorylation of IRS1. Although the PHiov phenotype did not show a decrease in the serine phosphorylation of IRS1, it was the group which presented higher recovery of all the alterations studied in this work. This allows us to suggest that tyrosine phosphorylation, coupled with the increase in the protein and gene expression of the insulin mediators (IR and IRS1) and in particular the recovery of GLUT4, is enough to restore the cyclicity of the estrous cycle.

Although the exact mechanism of action of metformin in the ovary is not yet clear, it has been demonstrated that metformin activates AMPK in bovine and mouse (Elia et al. 2006, Tosca et al. 2007). In agreement with these findings, here we found evidence that metformin acts through an AMP-dependent protein kinase. Considering this result and taking into account that metformin is able to regulate both protein and gene expression by phosphorylation of AMPK (Tosca et al. 2010, Rice et al. 2011), we suggest that the improvement of the alterations found in $\mathrm{PH}$ rats is partly due to the activation of AMPK. We also found that this activation was phenotypically differentiated, since PHiov rats displayed higher phosphorylation of AMPK than PHanov rats. Moreover, these results suggest that although fetal programming can cause longterm alterations, a correct treatment with metformin can reverse these effects, at least to some extent, thus improving the estrous cycle. Considering that the PHiov group has recovered better than the PHanov group, this could suggest that the more severe phenotypes could need longer treatment, a higher dose for the treatment to be more effective or a combined therapy with other drugs. A parallelism in PCOS patients is also observed, where in order to provide an adequate treatment, it is necessary to consider the patient phenotype and the severity and variety of the alterations (Badawy \& Elnashar 2011). Further research is needed to clarify if the less effective response to metformin treatment is due to the severity of the phenotype or to other mechanisms; thus, our model seems to be useful for such studies.

\section{Declaration of interest}

The authors declare that there is no conflict of interest that could be perceived as prejudicing the impartiality of the research reported.

\section{Funding}

This work was supported by grants from Agencia Nacional de Promoción Científica y Tecnológica (ANPCyT) (Grant PICT 632/2016 and PICT 689/2013), Argentina. M F H, SR F and G A A are supported by a doctoral fellowship awarded by CONICET. A B M and O P P are PhD from CONICET. M V is PhD from CONYCIT.

\section{Author contribution statement}

A B M, G A A, M V and M F H conceived and designed the experiments. G A A, M F H, S R F and O P P performed the experiments. G A A and M F H analyzed the data. G A A, M F H, SR F, M V and A B M contributed reagents/ materials/analysis tools. M F H and A B M wrote the paper. G A A, M F H, S $\mathrm{RF}$ and $\mathrm{A} B \mathrm{M}$ corrected and read the last version.

\section{Acknowledgements}

The authors thank Enzo Cuba and Marcela Marquez for their technical support in the animal care and the people from the Laboratorio de Endocrinología y Biología Reproductiva, Hospital Clínico Universidad de Chile for receiving me in their lab. 


\section{References}

Abbott DH, Dumesic DA \& Franks S 2002 Developmental origin of polycystic ovary syndrome - a hypothesis. Journal of Endocrinology 174 1-5. (https://doi.org/10.1677/joe.0.1740001)

Abbott DH, Bruns CR, Barnett DK, Dunaif A, Goodfriend TL, Dumesic DA \& Tarantal AF 2010 Experimentally induced gestational androgen excess disrupts glucoregulation in rhesus monkey dams and their female offspring. American Journal of Physiology. Endocrinology and Metabolism 299 E741-E751. (https://doi.org/10.1152/ ajpendo.00058.2010)

Abruzzese GA, Heber MF, Ferreira SR, Velez LM, Reynoso R, Pignataro OP \& Motta AB 2016 Prenatal hyperandrogenism induces alterations that affect liver lipid metabolism. Journal of Endocrinology 230 67-79. (https://doi.org/10.1530/JOE-15-0471)

Amalfi S, Velez LM, Heber MF, Vighi S, Ferreira SR, Orozco AV, Pignataro O \& Motta AB 2012 Prenatal hyperandrogenization induces metabolic and endocrine alterations which depend on the levels of testosterone exposure. PLoS One 7 e37658. (https://doi.org/10.1371/ journal.pone.0037658)

Amato MC, Verghi M, Nucera M, Galluzzo A \& Giordano C 2011 Low estradiol-to-testosterone ratio is associated with oligo-anovulatory cycles and atherogenic lipidic pattern in women with polycystic ovary syndrome. Gynecological Endocrinology 27 579-586. (https://doi. org/10.3109/09513590.2010.495797)

Badawy A \& Elnashar A 2011 Treatment options for polycystic ovary syndrome. International Journal of Women's Health 3 25-35. (https:// doi.org/10.2147/IJWH.S11304)

Barker DJ, Bagby SP \& Hanson MA 2006 Mechanisms of disease: in utero programming in the pathogenesis of hypertension. Nature Reviews Nephrology 2 700-707. (https://doi.org/10.1038/ncpneph0344)

Bateson P, Gluckman P \& Hanson M 2014 The biology of developmental plasticity and the Predictive Adaptive Response hypothesis. Journal of Physiology 592 2357-2368. (https://doi.org/10.1113/ jphysiol.2014.271460)

Book CB \& Dunaif A 1999 Selective insulin resistance in the polycystic ovary syndrome. Journal of Clinical Endocrinology and Metabolism $\mathbf{8 4}$ 3110-3116. (https://doi.org/10.1210/jcem.84.9.6010)

Bradford MM 1976 A rapid and sensitive method for the quantitation of microgram quantities of protein utilizing the principle of protein-dye binding. Analytical Biochemistry 72 248-254.

Burks DJ, de Mora JF, Schubert M, Withers DJ, Myers MG, Towery HH, Altamuro SL, Flint CL \& White MF 2000 IRS-2 pathways integrate female reproduction and energy homeostasis. Nature 407 377-382. (https://doi.org/10.1038/35030105)

Corbould A 2007 Chronic testosterone treatment induces selective insulin resistance in subcutaneous adipocytes of women. Journal of Endocrinology 192 585-594. (https://doi.org/10.1677/joe.1.07070)

Demissie M, Lazic M, Foecking EM, Aird F, Dunaif A \& Levine JE 2008 Transient prenatal androgen exposure produces metabolic syndrome in adult female rats. American Journal of Physiology. Endocrinology and Metabolism 295 E262-E268. (https://doi.org/10.1152/ ajpendo.90208.2008)

Diamanti-Kandarakis E \& Dunaif A 2012 Insulin resistance and the polycystic ovary syndrome revisited: an update on mechanisms and implications. Endocrine Reviews 33 981-1030. (https://doi org/10.1210/er.2011-1034)

Diamanti-Kandarakis E, Argyrakopoulou G, Economou F, Kandaraki E \& Koutsilieris M 2008 Defects in insulin signaling pathways in ovarian steroidogenesis and other tissues in polycystic ovary syndrome (PCOS). Journal of Steroid Biochemistry and Molecular Biology 109 242-246. (https://doi.org/10.1016/j.jsbmb.2008.03.014)

Diamanti-Kandarakis E, Christakou CD, Kandaraki E \& Economou FN 2010 Metformin: an old medication of new fashion: evolving new molecular mechanisms and clinical implications in polycystic ovary syndrome. European Journal of Endocrinology 162 193-212. (https:// doi.org/10.1530/EJE-09-0733)

Draznin B 2006 Molecular mechanisms of insulin resistance: serine phosphorylation of insulin receptor substrate-1 and increased expression of p85alpha: the two sides of a coin. Diabetes $\mathbf{5 5}$ 2392-2397. (https://doi.org/10.2337/db06-0391)

Dupont J \& Scaramuzzi RJ 2016 Insulin signalling and glucose transport in the ovary and ovarian function during the ovarian cycle. Biochemical Journal 473 1483-1501. (https://doi.org/10.1042/BCJ20160124)

Elia E, Sander V, Luchetti CG, Solano ME, Di Girolamo G, Gonzalez C \& Motta AB 2006 The mechanisms involved in the action of metformin in regulating ovarian function in hyperandrogenized mice. Molecular Human Reproduction 12 475-481. (https://doi.org/10.1093/molehr/ gal057)

Fernandez-Twinn DS, Constância M \& Ozanne SE 2015 Intergenerational epigenetic inheritance in models of developmental programming of adult disease. Seminars in Cell and Developmental Biology 43 85-95. (https://doi.org/10.1016/j.semcdb.2015.06.006)

Foecking EM, McDevitt MA, Acosta-Martínez M, Horton TH \& Levine JE 2008 Neuroendocrine consequences of androgen excess in female rodents. Hormones and Behavior 53 673-692. (https://doi. org/10.1016/j.yhbeh.2007.12.013)

Foretz M, Guigas B, Bertrand L, Pollak M \& Viollet B 2014 Metformin: from mechanisms of action to therapies. Cell Metabolism 20 953-966. (https://doi.org/10.1016/j.cmet.2014.09.018)

Fornes R, Ormazabal P, Rosas C, Gabler F, Vantman D, Romero C \& Vega M 2010 Changes in the expression of insulin signaling pathway molecules in endometria from polycystic ovary syndrome women with or without hyperinsulinemia. Molecular Medicine 16 129-136. (https://doi.org/10.2119/molmed.2009.00118)

Franks S, Mason H \& Willis D 2000 Follicular dynamics in the polycystic ovary syndrome. Molecular and Cellular Endocrinology 163 49-52. (https://doi.org/10.1016/S0303-7207(99)00239-7)

Galuska D, Nolte LA, Zierath JR \& Wallberg-Henriksson H 1994 Effect of metformin on insulin-stimulated glucose transport in isolated skeletal muscle obtained from patients with NIDDM. Diabetologia 37 826-832. (https://doi.org/10.1007/BF00404340)

Giannarelli R, Aragona M, Coppelli A \& Del Prato S 2003 Reducing insulin resistance with metformin: the evidence today. Diabetes and Metabolism 29 6S28-6S35. (https://doi.org/10.1016/S12623636(03)72785-2)

Godfrey KM \& Barker DJ 2001 Fetal programming and adult health. Public Health Nutrition 4 611-624. (https://doi.org/10.1079/PHN2001145)

Heber MF, Ferreira SR, Vélez LM \& Motta AB 2013 Prenatal hyperandrogenism and lipid profile during different age stages: an experimental study. Fertility and Sterility 99 551-557. (https://doi. org/10.1016/j.fertnstert.2012.10.017)

Hundal HS, Ramlal T, Reyes R, Leiter LA \& Klip A 1992 Cellular mechanism of metformin action involves glucose transporter translocation from an intracellular pool to the plasma membrane in L6 muscle cells. Endocrinology 131 1165-1173. (https://doi. org/10.1210/endo.131.3.1505458)

Hundal RS, Krssak M, Dufour S, Laurent D, Lebon V, Chandramouli V, Inzucchi SE, Schumann WC, Petersen KF, Landau BR, et al. 2000 Mechanism by which metformin reduces glucose production in type 2 diabetes. Diabetes 49 2063-2069. (https://doi.org/10.2337/ diabetes.49.12.2063)

Imano E, Kadowaki H, Kadowaki T, Iwama N, Watarai T, Kawamori R, Kamada T \& Taylor SI 1991 Two patients with insulin resistance due to decreased levels of insulin-receptor mRNA. Diabetes 40 548-557.

Jahanfar S, Eden JA, Warren P, Seppälä M \& Nguyen TV 1995 A twin study of polycystic ovary syndrome. Fertility and Sterility 63 478-486. (https://doi.org/10.1016/S0015-0282(16)57412-3)

Karim BO, Landolfi JA, Christian A, Ricart-Arbona R, Qiu W, McAlonis M, Eyabi PO, Khan KA, Dicello JF, Mann JF, et al. 2003 Estrous cycle and ovarian changes in a rat mammary carcinogenesis model after https://joe.bioscientifica.com https://doi.org/10.1530/JOE-18-0520 (c) 2019 Society for Endocrinology Published by Bioscientifica Ltd. Printed in Great Britain 
irradiation, tamoxifen chemoprevention, and aging. Comparative Medicine 53 532-538.

Kim J, Yang G, Kim Y, Kim J \& Ha J 2016 AMPK activators: mechanisms of action and physiological activities. Experimental and Molecular Medicine 48 e224. (https://doi.org/10.1038/emm.2016.16)

Lord JM, Flight IHK \& Norman RJ 2003 Metformin in polycystic ovary syndrome: systematic review and meta-analysis. BMJ 327 951-953. (https://doi.org/10.1136/bmj.327.7421.951)

Ma HM, Chen DM, Xiang L, Liu CQ, Hou QN, He YT, Xin C, Zhang YF, Pei XY, Wang YR, et al. 2018 Effect of metformin-induced stimulation on the expression of insulin receptor Substrate 1 through negative regulation of p70s6K. Reproductive and Developmental Medicine 2 15-20. (https://doi.org/10.4103/2096-2924.232874)

Manikkam M, Steckler TL, Welch KB, Inskeep EK \& Padmanabhan V 2006 Fetal programming: prenatal testosterone treatment leads to follicular persistence/luteal defects; partial restoration of ovarian function by cyclic progesterone treatment. Endocrinology 147 1997-2007. (https:// doi.org/10.1210/en.2005-1338)

Mathur R, Alexander CJ, Yano J, Trivax B \& Azziz R 2008 Use of metformin in polycystic ovary syndrome. American Journal of Obstetrics and Gynecology 199 596-609. (https://doi.org/10.1016/j.ajog.2008.09.010)

Matthews DR, Hosker JP, Rudenski AS, Naylor BA, Treacher DF \& Turner RC 1985 Homeostasis model assessment: insulin resistance and $\beta$-cell function from fasting plasma glucose and insulin concentrations in man. Diabetologia 28 412-419. (https://doi.org/10.1007/BF00280883)

Nada SE, Thompson RC \& Padmanabhan V 2010 Developmental programming: differential effects of prenatal testosterone excess on insulin target tissues. Endocrinology 151 5165-5173. (https://doi. org/10.1210/en.2010-0666)

Padmanabhan V, Manikkam M, Recabarren S \& Foster D 2006 Prenatal testosterone excess programs reproductive and metabolic dysfunction in the female. Molecular and Cellular Endocrinology 246 165-174. (https://doi.org/10.1016/j.mce.2005.11.016)

Paz K, Hemi R, LeRoith D, Karasik A, Elhanany E, Kanety H \& Zick Y 1997 A molecular basis for insulin resistance. Elevated serine/threonine phosphorylation of IRS-1 and IRS-2 inhibits their binding to the juxtamembrane region of the insulin receptor and impairs their ability to undergo insulin-induced tyrosine phosphorylation. Journal of Biological Chemistry 272 29911-29918. (https://doi.org/10.1074/jbc.272.47.29911)

Poretsky L, Cataldo NA, Rosenwaks Z \& Giudice LC 1999 The insulinrelated ovarian regulatory system in health and disease. Endocrine Reviews 20 535-582. (https://doi.org/10.1210/edrv.20.4.0374)

Recabarren SE, Recabarren M, Sandoval D, Carrasco A, Padmanabhan V, Rey R, Richter HG, Perez-Marin CC, Sir-Petermann T \& Rojas-Garcia PP 2017 Puberty arises with testicular alterations and defective AMH expression in rams prenatally exposed to testosterone. Domestic Animal Endocrinology 61 100-107. (https://doi.org/10.1016/j. domaniend.2017.06.004)

Rice S, Christoforidis N, Gadd C, Nikolaou D, Seyani L, Donaldson A, Margara R, Hardy K \& Franks S 2005 Impaired insulin-dependent glucose metabolism in granulosa-lutein cells from anovulatory women with polycystic ovaries. Human Reproduction 20 373-381. (https://doi.org/10.1093/humrep/deh609)

Rice S, Pellatt LJ, Bryan SJ, Whitehead SA \& Mason HD 2011 Action of metformin on the insulin-signaling pathway and on glucose transport in human granulosa cells. Journal of Clinical Endocrinology and Metabolism 96 E427-E435. (https://doi.org/10.1210/jc.2010-2060)

Rincon J, Holmäng A, Wahlström EO, Lönnroth P, Björntorp P, Zierath JR \& Wallberg-Henriksson H 1996 Mechanisms behind insulin resistance in rat skeletal muscle after oophorectomy and additional testosterone treatment. Diabetes 45 615-621.
Ryan BC \& Vandenbergh JG 2002 Intrauterine position effects. Neuroscience and Biobehavioral Reviews 26 665-678. (https://doi. org/10.1016/S0149-7634(02)00038-6)

Saltiel AR \& Kahn CR 2001 Insulin signalling and the regulation of glucose and lipid metabolism. Nature $\mathbf{4 1 4}$ 799-806. (https://doi. org/10.1038/414799a)

Swillens S, Dessars B \& Housni HE 2008 Revisiting the sigmoidal curve fitting applied to quantitative real-time PCR data. Analytical Biochemistry 373 370-376. (https://doi.org/10.1016/j.ab.2007.10.019)

Tosca L, Chabrolle C, Uzbekova S \& Dupont J 2007 Effects of metformin on bovine granulosa cells steroidogenesis: possible involvement of adenosine 5' monophosphate-activated protein kinase (AMPK). Biology of Reproduction 76 368-378. (https://doi.org/10.1095/ biolreprod.106.055749)

Tosca L, Ramé C, Chabrolle C, Tesseraud S \& Dupont J 2010 Metformin decreases IGF1-induced cell proliferation and protein synthesis through AMP-activated protein kinase in cultured bovine granulosa cells. Reproduction 139 409-418. (https://doi.org/10.1530/REP-09-0351)

Viollet B, Guigas B, Sanz Garcia N, Leclerc J, Foretz M \& Andreelli F 2012 Cellular and molecular mechanisms of metformin: an overview. Clinical Science 122 253-270. (https://doi.org/10.1042/CS20110386)

Watson RT \& Pessin JE 2001 Subcellular compartmentalization and trafficking of the insulin-responsive glucose transporter, GLUT4. Experimental Cell Research 271 75-83. (https://doi.org/10.1006/ excr.2001.5375)

White MF 2002 IRS proteins and the common path to diabetes. American Journal of Physiology. Endocrinology and Metabolism 283 E413-E422. (https://doi.org/10.1152/ajpendo.00514.2001)

Wolf CJ, Hotchkiss A, Ostby JS, LeBlanc GA \& Gray LE 2002 Effects of prenatal testosterone propionate on the sexual development of male and female rats: a dose-response study. Toxicological Sciences 65 71-86. (https://doi.org/10.1093/toxsci/65.1.71)

Wu XK, Zhou SY, Liu JX, Pöllänen P, Sallinen K, Mäkinen M \& Erkkola R 2003 Selective ovary resistance to insulin signaling in women with polycystic ovary syndrome. Fertility and Sterility 80 954-965. (https:// doi.org/10.1016/S0015-0282(03)01007-0)

Wu L, Cai X, Dong H, Jing W, Huang Y, Yang X, Wu Y \& Lin Y 2010 Serum regulates adipogenesis of mesenchymal stem cells via MEK/ ERK-dependent PPAR $\gamma$ expression and phosphorylation. Journal of Cellular and Molecular Medicine 14 922-932. (https://doi.org/10.1111/ j.1582-4934.2009.00709.x)

Wu Y, Li P, Zhang D \& Sun Y 2018 Metformin and pioglitazone combination therapy ameliorate polycystic ovary syndrome through AMPK/PI3K/JNK pathway. Experimental and Therapeutic Medicine 15 2120-2127. (https://doi.org/10.3892/etm.2017.5650)

Xu H, Zhou Y, Liu Y, Ping J, Shou Q, Chen F \& Ruo R 2016 Metformin improves hepatic IRS2/PI3K/Akt signaling in insulin-resistant rats of NASH and cirrhosis. Journal of Endocrinology 229 133-144. (https:// doi.org/10.1530/JOE-15-0409)

Zhao S, Xu H, Cui Y, Wang W, Qin Y, You L, Chan WY, Sun Y \& Chen ZJ 2016 Metabolic actions of insulin in ovarian granulosa cells were unaffected by hyperandrogenism. Endocrine 53 823-830. (https://doi. org/10.1007/s12020-016-0949-y)

Zhou G, Myers R, Li Y, Chen Y, Shen X, Fenyk-Melody J, Wu M, Ventre J, Doebber T, Fujii N, et al. 2001 Role of AMP-activated protein kinase in mechanism of metformin action. Journal of Clinical Investigation $\mathbf{1 0 8}$ 1167-1174. (https://doi.org/10.1172/JCI13505)

Zielinski WJ, Vandenbergh JG \& Montano MM 1991 Effects of social stress and intrauterine position on sexual phenotype in wild-type house mice (Mus musculus). Physiology and Behavior 49 117-123. (https://doi.org/10.1016/0031-9384(91)90241-F)

Received in final form 23 December 2018

Accepted 8 January 2019

Accepted Preprint published online 8 January 2019 https://joe.bioscientifica.com https://doi.org/10.1530/JOE-18-0520 (c) 2019 Society for Endocrinology Published by Bioscientifica Ltd. Printed in Great Britain 